\title{
Combined use of LC-ESI-MS and antifungal tests for rapid identification of bioactive lipopeptides produced by Bacillus amyloliquefaciens CCMI 1051
}

\author{
Ana Teresa Caldeira ${ }^{\mathrm{a}, \mathrm{b}, *}$, J.M. Santos Arteiro ${ }^{\mathrm{a}, \mathrm{b}}$, Ana V. Coelho ${ }^{\mathrm{a}, \mathrm{c}}$, J. Carlos Roseiro ${ }^{\mathrm{d}}$ \\ a Universidade de Évora, Departamento de Química, Rua Romão Ramalho no 59, 7000-671 Évora, Portugal \\ b Centro de Química de Évora, Rua Romão Ramalho no 59, 7000-671 Évora, Portugal \\ ' Instituto de Tecnologia Química e Biológica, Universidade Nova de Lisboa, Av. da República, Apt. 127, 2781-901 Oeiras, Portugal \\ ${ }^{\mathrm{d}}$ Laboratório Nacional de Energia e Geologia, Unidade de Bioenergia, Azinhaga dos Lameiros 22, 1648-038 Lisboa, Portugal
}

\section{A R T I C L E I N F O}

\section{Article history:}

Received 20 January 2011

Received in revised form 10 April 2011

Accepted 27 May 2011

\section{Keywords:}

Antimicrobial activity

Bacillus amyloliquefaciens

Cyclic lipopeptides

Iturin

Biosurfactants

\begin{abstract}
A B S T R A C T
The strain Bacillus amyloliquefaciens CCMI 1051 used in this study has been isolated in our laboratory from healthy Quercus suber in the south of Portugal and shows high levels of antagonistic properties against filamentous fungi that attack forest products industry due to the production of bioactive peptides.

A combined use of LC-ESI-MS and antifungal tests allowed a rapid identification of lipopeptides as active compounds produced. Applying autobiographic methods it was possible to obtain active compounds. LC-ESI-MS, a powerful tool for rapid identification, indicates the presence of lipopeptides and MS $^{2}$ electrospray ionization showed the partial sequence Tyr-Asn-Pro-Glu in the peptidic portion of some compounds produced. The association of mass spectrometry and chromatography, used in parallel with antifungal tests proved to be an efficient approach for the characterization of active lipopeptides without the need of previous total isolation. This methodology can be employed for screening and optimization the production of antifungal iturinic lipopeptides, showing a great potential for future application.
\end{abstract}

(C) 2011 Elsevier Ltd. All rights reserved.

\section{Introduction}

Several strains of Bacillus subtilis and Bacillus amyloliquefaciens have been referred to produce lipopeptides. In response to nutritional stress, a variety of processes are activated by Bacillus strains, including sporulation, synthesis of extracellular degradative enzymes and antibiotic production [1,2]. Many strains are known to suppress fungal growth in vitro due to the production of antifungal antibiotics [3-6] especially the nonribosomally synthesized cyclic lipopetides surfactin, iturin and fengycin. Bioactive peptides show a great potential for biotechnological, biopharmaceutical and agricultural applications. Among the most promising candidates for bacterial biocontrol agents are several species of the genus Bacillus, their ability to sporulate, assures their prevalence in the environment and guarantees future suitable formulation strategies [7]. The lipopeptides surfactin, fengycin and iturin are amphiphilic membrane-active biosurfactants and peptide antibiotics with potent antifungal activities [8,9], which can be used as biopesticides for plant protection. These compounds, made of

\footnotetext{
* Corresponding author at: Universidade de Évora, Departamento de Química, Rua Romão Ramalho no 59, 7000-671 Évora, Portugal. Tel.: +351 266745 313; fax: +351266745303.

E-mail address: atc@uevora.pt (A.T. Caldeira).
}

amino acids and a fatty acid, are easily biodegradable in the soils [10]. In recent years, there is a considerable interest in using Bacillus producing lipopeptide antibiotics like iturin $\mathrm{A}$ and surfactin as a biocontrol agent due to its antagonistic and repressive activity over plant pathogens [11]. These amphiphilic cyclic biosurfactants have many advantages over other pesticides: low toxicity, high biodegradability and environmentally friendly characteristics [6,12-15]. In literature, several approaches for lipopeptide identification have been proposed but their biological activity needs to be determined after isolation procedures [16-19]. The Bacillus strain, used in this study, Genbank access number AY785773, has been isolated in our laboratory from Quercus suber and shows high levels of antagonistic properties against filamentous fungi that attack industrial forest products. The purpose of this study was to access a rapid characterization of the unidentified active metabolites produced by B. amyloliquefaciens CCMI 1051 using LC-ESI-MS analysis and monitoring, by antifungal tests, active metabolites without previous total isolation. MS/MS was employed separately to establish the partial sequence of each active compound after isolation.

\section{Materials and methods}

\subsection{Microoganisms and inocula preparation}

The B. amyloliquefaciens CCMI 1051 used throughout this study has been isolated in our laboratory from $Q$. suber. The strain was characterized by the morpholog- 